\title{
THE ECONOMICALLY OPTIMAL DESIGN OF HEAT EXCHANGERS
}

\author{
H.J. Fontein and J. Groot Wassink \\ Department of Chemical Engineering, Twente University of Technology, Enschede (The Netherlands)
}

\begin{abstract}
A new method to design heat exchangers is proposed, which is based on the process description by Kays and London and lends itself very well to optimization.

The method is described by applying it to the economic optimization of a countercurrent exchanger, the extension to other flow configurations being selfexplanatory.
\end{abstract}

\section{INTRODUCTION}

According to the process description of heat exchangers by Kays and London [1] the number of overall heat transfer units, NTU, can be computed as a function of the efficiency $\epsilon$, the ratio between the heat capacity rates of both fluids, and the flow configuration. This description offers some advantages over the traditional log mean temperature approach, the most important ones being the thermodynamic significance of $\epsilon$ and the greater ease of computation.

From the NTU a value for the product of the overall heat transfer coefficient and the required exchanger surface is obtained. Both depend on the lay-out of the exchanger and on the process conditions in a rather complicated way. A suitable rearrangement of the pertinent equations and a judicious choice of the design variables result in an acyclic computational scheme, which because of its straightforwardness is well adapted to an optimization program.

\section{THE DESIGN PROCEDURE}

The problem to be solved is the optimal design of a heat exchanger for a specified duty, i.e. the two flows and their entrance and exit temperatures are known.

Dodge [2] introduced the heat transfer effectiveness, which is defined as the ratio between the actual heat transfer rate and the maximum possible rate, as would be realized only in a counterflow exchanger of infinite transfer area:

$\epsilon=\frac{C_{\mathrm{h}}\left(t_{\mathrm{h}, \text { in }}-t_{\mathrm{h}, \text { out }}\right)}{C_{\min }\left(t_{\mathrm{h}, \text { in }}-t_{\mathrm{c}, \text { in }}\right)}=\frac{C_{\mathrm{c}}\left(t_{\mathrm{c}, \text { out }}-t_{\mathrm{c}, \text { in }}\right)}{C_{\min }\left(t_{\mathrm{h}, \text { in }}-t_{\mathrm{c}, \text { in }}\right)}$

Kays and London [1] found that it is possible to express $\epsilon$ as a function of NTU, $\gamma=C_{\min } / C_{\max }$ and the flow arrangement; in the case of counterflow for instance:

$\epsilon=\frac{1-\exp (-\operatorname{NTU}(1-\gamma))}{1-\gamma \exp (-\operatorname{NTU}(1-\gamma))}$

or 


$$
\mathrm{NTU}=\frac{\ln \left(\frac{1-\epsilon \gamma}{1-\epsilon}\right)}{1-\gamma}
$$

One of the more common arrangements for shell and tube construction is multipass cross counterflow; it is realized by baffling the flow around the tubes.

The $\epsilon-$ NTU relation for this arrangement depends on the number of passes, the above given counterflow relation being its limit if this number tends to infinity [1]. If the number of passes is higher than 3 the counterflow relations can be used as an acceptable approximation. Eq. 1 can be written as:

$\epsilon=\frac{C_{1}\left(t_{1, \text { in }}-t_{1, \text { out }}\right)}{C_{\min }\left(t_{1, \text { in }}-t_{2, \text { in }}\right)}=\frac{C_{2}\left(t_{2, \text { out }}-t_{2}, \text { in }\right)}{C_{\min }\left(t_{1, \text { in }}-t_{2, \text { in }}\right)}$

where the indices 1 and 2 apply to the flow through and around the tubes respectively.

Use of eq. 1 a as compared to eq. 1 simplifies the computer program because it now is unnecessary to specify whether the hot or the cold fluid flows through the tubes.

With the NTU, which is an overall figure, two partial ntu's correspond. Combining the definitions

$\mathrm{NTU}=\frac{U A}{C_{\min }}=\frac{U_{1} A_{1}}{C_{\min }}$

and

ntu $_{\mathrm{k}}=\frac{\alpha_{\mathrm{k}} A_{\mathrm{k}}}{C_{\mathrm{k}}} \quad \mathrm{k} \epsilon \quad\{1,2\}$

with the overall heat transfer equation

$\frac{1}{U_{1} A_{1}}=\frac{1}{\alpha_{3} A_{1}}+\frac{1}{\alpha_{2} A_{2}}+\frac{2 d_{\mathrm{W}}}{\lambda_{\mathrm{W}}\left(A_{1}+A_{2}\right)}+\frac{u_{1}}{A_{1}}+\frac{u_{2}}{A_{2}}$

the following relation is obtained:

$\frac{1}{\mathrm{NTU}}=C_{\min }\left(\frac{1}{C_{1} \mathrm{ntu}_{1}}+\frac{1}{C_{2} \mathrm{ntu}_{2}}+\frac{2 d_{\mathrm{W}}}{\lambda_{\mathrm{W}}\left(A_{1}+A_{2}\right)}+\frac{u_{1}}{A_{1}}+\frac{u_{2}}{A_{2}}\right) \mathrm{Re}_{1}=\frac{\phi_{1} \cdot 4 r_{\mathrm{h}, 1}}{A_{\mathrm{C}, 1} \cdot \nu_{1}}$
To describe the dependence of ntu on the hydrodynamic conditions and geometrical dimensions, equations are derived as follows.

Neglecting the potential and kinetic energy terms reduces the Bernoulli equation to:

$\int_{1}^{2} \frac{d p}{P}+{ }_{1}^{2} \int d w=0$

Introducing the Fanning equation and integrating:

$\frac{\Delta p}{\rho}={ }_{1}^{2} \int f \cdot \frac{1}{2} v^{2} \cdot \frac{\mathrm{d} L}{r_{\mathrm{h}}}=f \cdot \frac{L}{r_{\mathrm{h}}} \cdot \frac{1}{2} v^{2}$

or

$\mathrm{Eu} \equiv \frac{p}{1 / 2 \rho v^{2}}=f \frac{L}{r_{\mathrm{h}}}$

Because $C=\rho \nu A_{\mathrm{c}} C p$ :

$\mathrm{St} \equiv \frac{\alpha}{v \rho C_{\mathrm{p}}}=\frac{\alpha A_{\mathrm{c}}}{C}=\mathrm{ntu} \frac{A_{\mathrm{c}}}{A}=\mathrm{ntu} \frac{r_{\mathrm{h}}}{L}$

Combining with

$j_{\mathrm{h}} \equiv \mathrm{St} \operatorname{Pr} 2 / 3$

it is apparent that

$\frac{L}{r_{h}}=\frac{n t u}{S t}=\frac{n t u}{i_{h}} \operatorname{Pr}^{2 / 3}$

and, from eq. 4

$\mathrm{Eu}=f \frac{\mathrm{ntu}}{j_{\mathrm{h}}} \operatorname{Pr}^{2 / 3}$

Relations 4 and 5 apply to both flows in the heat exchanger.

For the flow through the tubes the following equations hold:

$4 r_{\mathrm{h}, 1}=d_{0}-2 d_{\mathrm{w}}$ 
$A_{\mathrm{c}, 1}=n \frac{\pi}{4}\left(d_{0}-2 d_{\mathrm{W}}\right)^{2}$

or

$\operatorname{Re}_{1}=\frac{4 \phi_{1}}{n \pi\left(d_{0}-2 d_{\mathrm{w}}\right) \nu_{1}}$

If the flow is turbulent

$i_{\mathrm{h}, 1}=0.027 \operatorname{Re}_{1}-0.2$

and

$f_{1}=0.05 \operatorname{Re}_{1}-0.2$

For the flow around the tubes, which is assumed to be baffled, acyclicity of the computational structure requires a rearrangement of the equations:

$\operatorname{Re}_{2}=\frac{\phi_{2} \cdot 4 r_{\mathrm{h}, 2}}{A_{\mathrm{c}, 2} \cdot \nu_{2}}$

$4 r_{\mathrm{h}, 2}=d_{0} A_{\mathrm{X}}$

where $A_{\mathrm{x}}$ depends on the tube configuration.

$A_{\mathrm{C}, 2} \cong 2 \frac{s-d}{s} \quad D B=2\left(1-\frac{1}{X}\right) D B$

and consequently

$\operatorname{Re}_{2}=\frac{\phi_{2} d_{0} A_{\mathrm{X}}}{2\left(1-\frac{1}{X}\right) D B \nu_{2}}$

Because of

$j_{\mathrm{h}, 2}=C_{\mathrm{n}} \operatorname{Re}_{2}^{-0.4}$

eliminating $\mathrm{Eu}_{2}$ from eq. 4 and 5 leads to:

$L_{2}=\frac{d_{0} A_{\mathrm{X}} \mathrm{ntu}_{2} \operatorname{Pr}_{\mathrm{s}}^{2 / 3}}{4 C_{\mathrm{n}} \operatorname{Re}_{2}^{-0.4}}$

From the geometry of the exchanger it follows that:
$L_{2}=\frac{L_{1}}{B} \quad D \quad$ and thus:

$B=\frac{4 C_{\mathrm{n}_{2} \mathrm{Re}_{2}}^{-0.4} L_{1} D}{d_{\mathrm{a}} A_{\mathrm{X} \mathrm{ntu}_{2} \operatorname{Pr}_{2}}{ }^{2 / 3}}$

Elimination of respectively $B$ and $\mathrm{Re}_{2}$ from the above expression for $\mathrm{Re}_{2}$ and $B$ results in the two following equations:

$$
\begin{aligned}
\operatorname{Re}_{2}= & \left(\frac{\phi_{2}}{\nu_{2}\left(1-\frac{1}{X}\right) L_{1}}\right)^{5 / 3} \cdot\left(\frac{\mathrm{ntu}_{2}}{8 C_{\mathrm{r}}}\right)^{5 / 3} \cdot \\
& \left(\frac{d_{0} A_{\mathrm{X}}}{D}\right)^{10 / 3} \cdot \operatorname{Pr}_{2} 10 / 9 \\
\frac{D}{L_{1}=\frac{1}{2}} & \left(\frac{\nu_{2}\left(1-\frac{1}{X}\right) L_{2}}{\phi_{2}}\right)^{2 / 3} \cdot\left(\frac{8 C_{\mathrm{n}}}{\mathrm{ntu}}\right)^{5 / 3} \cdot \\
& \left(\frac{D}{d_{0} A_{\mathrm{X}}}\right)^{7 / 3} \cdot \operatorname{Pr}_{2}-10 / 9
\end{aligned}
$$

To compute $\mathrm{Eu}_{2}$ the following equation is used

$f_{2}=C_{\mathrm{f}} \operatorname{Re}_{2}^{-0.18}$

From the tube configuration two equations can be derived. For triangular pitch for instance

$A_{\mathrm{X}}=\frac{2 X^{2} \sqrt{ } 3}{\pi}-1$

and [3] :

$D=D\left(d_{0}, X, n\right)$

The coefficients $C_{\mathrm{n}}$ and $C_{\mathrm{f}}$ in the eq. 10 and 13 also depend on the tube configuration [1]:

$$
C_{\mathrm{n}}=C_{\mathrm{n}}(X)
$$


$C_{\mathrm{f}}=C_{\mathrm{f}}(X)$

It is obvious that:

$A_{1}=n \pi\left(d_{0}-2 d_{\mathrm{W}}\right) L_{1}$

and:

$A_{2}=n \pi d_{0} L_{1}$

The wall thickness of the tubes depends on the tube diameter and the pressures of the two fluids:

$d_{\mathrm{W}}=d_{\mathrm{W}}\left(d_{0}, P\right)$

The set of eq. 3 through 20 has 4 degrees of freedom. To choose suitable design variables the algorithm proposed by Lee et al. [4] was used. The following two sets result in acyclic computational schemes:

$\mathrm{I}:\left(D, \mathrm{ntu}_{1}, X, d_{0}\right)$

II: $\left(L_{1}, \dot{n}, X, d_{0}\right)$

The scheme using set I is illustrated in Fig. 1 .

\section{THE OPTIMIZATION}

To find the economically optimal design an objective function relating the costs to the design variables has to be constructed. Two kinds of costs are considered: depreciation on investment and operating costs.

To estimate the investment a number of methods has been proposed [5-8]. The first three methods relate the investment to the heat transfer area only; the procedure given by Palen [8] is a logical supplement to the above design procedure because according to it investment is calculated from the dimensions of the component parts of the exchanger and the manufacturing costs.

Among the operating costs only the costs of pumping the fluids through the exchanger are dependent on the design variables; they can be estimated from the throughputs and the pressure losses, which follow immediately from the Eu numbers (eq. 4).

To optimize the objective function two optimization procedures were tried: the complex method of Nelder and Mead [9] and a steepest descent method [10]. Both methods require continuous variables. Tubes being commercially available at discrete values of diameter and wall thickness only, the diameter was not included among the design variables; to find the optimal diameter the program is run for different tube diameters. The optimal wall thickness is the smallest standard thickness that is compatible with eq. 20 . The matter is further discussed under the heading "results". I'wo of the design variables are bound by constraints. Too small a value of $\mathrm{ntu}_{1}$ results in a negative value of $\mathrm{ntu}_{2}$ (eq. 3 ); if $X<1$ the first term at the right hand side of eq. 11 is undefined. An upper boundary on $X$ had to be introduced because literature data on the dependency of $C_{\mathrm{n}}$ and $C_{\mathrm{f}}$ on $X$ are available only for $X<1.65$ [1].

The last boundary is handled with a quadratic loss penalty function [11]; if any of the first 2 boundaries happens to be violated no design is possible and an arbitrarily chosen high value is assigned to the objective function.

To avoid practical difficulties the ratio $\beta$ between tube length and baffle distance should be an integer. Both are dependent variables; introduction of this constraint would result in discontinuities in the objective function. Therefore, the mathematically optimal design has to be adapted. This can be done in several ways, the easiest one being as follows.

A new baffle distance is computed by rounding off $\beta$ to the nearest integer value. This leads to new values for $\mathrm{Re}_{2}, \mathrm{Eu}_{2}, \mathrm{NTU}$ and $\epsilon$.

As a consequence the adapted heat exchanger does not satisfy the original specifica- 


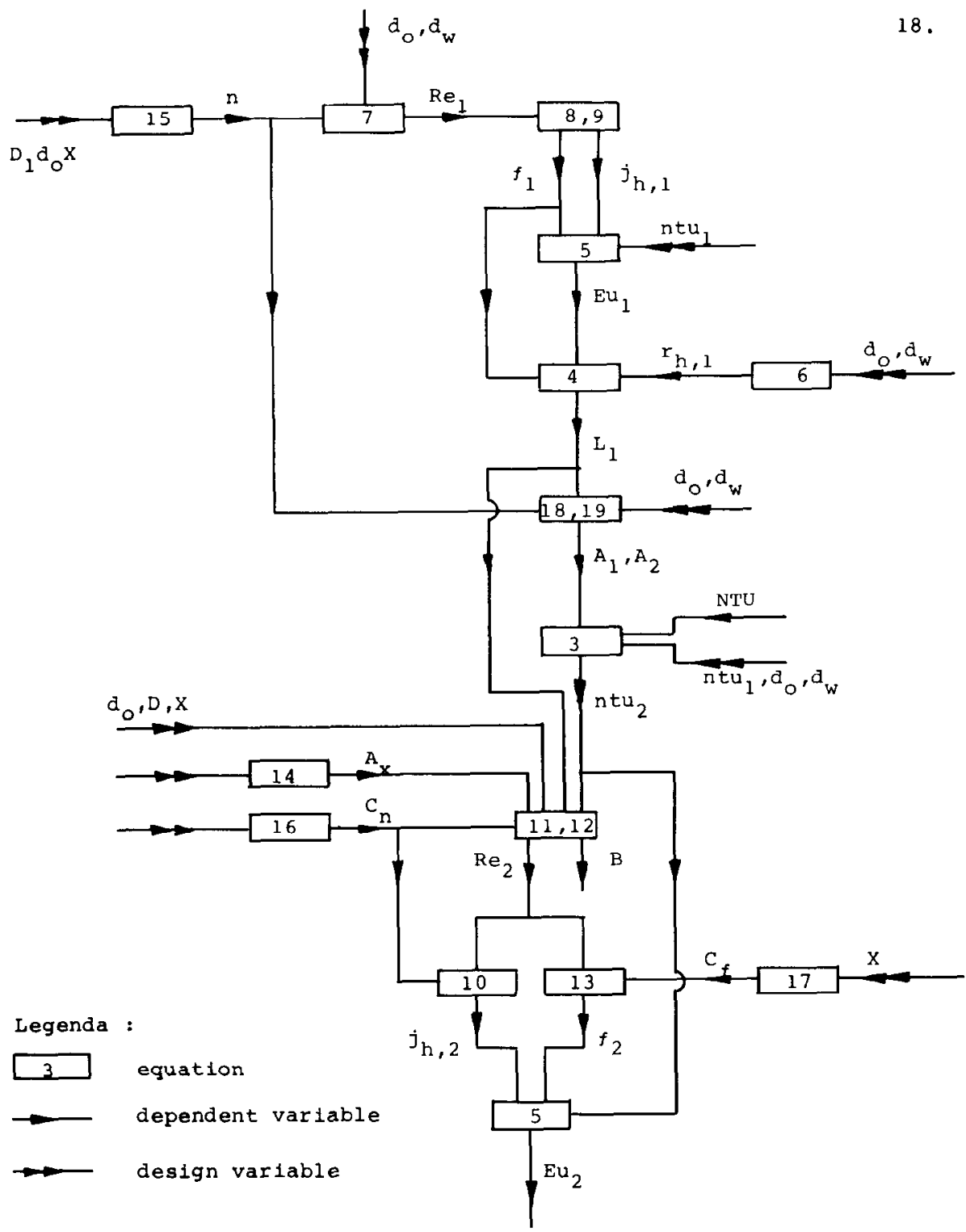

Fig. 1. Computational scheme in heat exchanger design.

tions. The deviations will be smaller at higher values of $\beta$; if this value should prove to be too small another type of flow pattern should be chosen anyway because the physical model would not apply.

Another consequence is that the costs of the final design are no longer mathematically optimal. Extensive experience, however, has taught that the optima are rather flat and the differences in the costs negligible.
To change the specifications eq. 1 a are used; inspection of these shows that several ways are open, the easiest one perhaps being recomputing both exit temperatures.

\section{RESULTS AND DISCUSSION}

An algol program comprising the above features was implemented on a DEC-10 com- 
puter. For relations that are given in graphical $[16,17]$ or in tabular form [15] virial cquations were derived from the data by means of the least squares method. As an illustration, the results obtained for a heat exchanger in which two streams of air are treated at atmospheric pressure are discussed.

Table 1 gives the input data. The investment costs obtained with the Palen model were multiplied by a factor 3 to allow for inflation and installation; the depreciation rate was put at 10 years. To estimate the pumping costs an energy price of $5 \mathrm{c} / \mathrm{kWh}$ was used.

TABLE 1

Input data

\begin{tabular}{|c|c|c|c|}
\hline & & In tubes & Around tubes \\
\hline$t_{\text {in }}$ & $\left({ }^{\circ} \mathrm{C}\right)$ & 370 & 40 \\
\hline$t_{\text {out }}$ & $\left.{ }^{\circ} \mathrm{C}\right)$ & 94 & 270 \\
\hline$\phi$ & $\left(\mathrm{m}^{3} / \mathrm{sec}\right)$ & 2.5 & 3 \\
\hline$d_{\mathrm{o}}$ & $(\mathrm{mm})$ & \multicolumn{2}{|c|}{26.9} \\
\hline$d_{\mathrm{w}}$ & $(\mathrm{mm})$ & \multicolumn{2}{|c|}{2.65} \\
\hline$\rho$ & $\left(\mathrm{kg} / \mathrm{m}^{3}\right)$ & \multicolumn{2}{|c|}{0.596} \\
\hline$c_{\mathrm{p}}$ & $\left(\mathrm{J} /{ }^{\circ} \mathrm{C} \mathrm{kg}\right)$ & \multicolumn{2}{|c|}{1040} \\
\hline$\nu^{r}$ & $\left(\mathrm{~m}^{2} / \mathrm{sec}\right)$ & \multicolumn{2}{|c|}{0.000041} \\
\hline$\lambda$ & $\left(\mathrm{J} /{ }^{\circ} \mathrm{C} \sec \mathrm{m}\right)$ & \multicolumn{2}{|c|}{0.042} \\
\hline$\lambda_{W}$ & $\left(\mathrm{~J} /{ }^{\circ} \mathrm{C} \sec \mathrm{m}\right)$ & \multicolumn{2}{|c|}{60} \\
\hline$u$ & $\left(\mathrm{~J} /{ }^{\circ} \mathrm{Csec} \mathrm{m}^{2}\right)$ & 0.0003 & 0.0003 \\
\hline
\end{tabular}

Table 2 gives the mathematical optima reached by the Nelder Mead and steepest descent methods after 217 and 95 functions calls respectively; in both cases the set I design variables were used. The small difference between the two optimal values strongly suggests that they are reliable

TABLE 2

Mathematical optima

\begin{tabular}{lllll} 
& $D$ & $\mathrm{ntu}_{1}$ & $X$ & $F$ \\
\hline Starting point & 0.8 & 8.5 & 1.1 & $2.1510^{5}$ \\
& & & & \\
$\begin{array}{l}\text { Mathematical optimum } \\
\quad \text { Nelder Mead }\end{array}$ & 1.2191 & 6.0922 & 1.6358 & 5129.9466 \\
$\quad$ Steepest Descent & 1.2191 & 6.0926 & 1.6356 & 5129.9465 \\
\hline
\end{tabular}

estimates of the true minimum, which is further borne out by the decrease of the gradient of the objective function (Table 3) and by the fact that use of the set II decision variables leads to virtually the same results.

\section{TABLE 3}

Gradients of the objective function

\begin{tabular}{llll} 
& $\delta \mathrm{F} / \delta \mathrm{D}$ & $\delta \mathrm{F} / \delta \mathrm{ntu}_{1}$ & $\delta \mathrm{F} / \delta \mathrm{X}$ \\
\hline Starting point & $4.3 \times 10^{5}$ & $1.8 \times 10^{5}$ & $-4.0 \times 10^{6}$ \\
Optimum & $3.9 \times 10^{-1}$ & $7.7 \times 10^{-2}$ & $-1.6 \times 10^{-1}$ \\
\hline
\end{tabular}

Table 4 gives the final optimal design. Comparing this table with Table 2 it can be seen that the relative difference between the total costs of the final design and the mathematical optimum is only about $1 \%$.

Table 5 illustrates the influence of energy price on the optimal design. As might be

\section{TABLE 4}

Final optimal design

\begin{tabular}{|c|c|c|}
\hline & In tubes & Around tubes \\
\hline$t_{\text {out }}\left({ }^{\circ} \mathrm{C}\right)$ & 90.54 & 272.88 \\
\hline$D(\mathrm{~m})$ & \multicolumn{2}{|c|}{1.219} \\
\hline$L(\mathrm{~m})$ & \multicolumn{2}{|c|}{4.943} \\
\hline$B(\mathrm{~m})$ & \multicolumn{2}{|c|}{0.989} \\
\hline$n$ & \multicolumn{2}{|c|}{624} \\
\hline$X$ & \multicolumn{2}{|c|}{1.636} \\
\hline$\epsilon$ & \multicolumn{2}{|c|}{0.847} \\
\hline NTU & \multicolumn{2}{|c|}{3.919} \\
\hline$U^{a}\left(\mathrm{~J} /{ }^{\circ} \mathrm{C} \sec \mathrm{m}^{2}\right)$ & 29.04 & 23.31 \\
\hline ntu & 6.09 & 9.61 \\
\hline$\alpha\left(\mathrm{J} /{ }^{\circ} \mathrm{C} \sec \mathrm{m}^{2}\right)$ & 45.14 & 68.58 \\
\hline $\mathrm{Re}$ & 5723 & 4068 \\
\hline $\mathrm{Eu}$ & 8.11 & 43.39 \\
\hline$A\left(\mathrm{~m}^{2}\right)$ & 209 & 260 \\
\hline$v(\mathrm{~m} / \mathrm{sec})$ & 10.9 & 6.4 \\
\hline$\Delta P(\mathrm{~atm})$ & 0.0029 & 0.0013 \\
\hline$\eta$ & \multicolumn{2}{|c|}{0.0055} \\
\hline Depreciation & \multirow{2}{*}{\multicolumn{2}{|c|}{4301}} \\
\hline$(\$ / y r)$ & & \\
\hline Pumping costs & \multirow{2}{*}{\multicolumn{2}{|c|}{940}} \\
\hline$(\$ / y r)$ & & \\
\hline Total $\left.\$ / \mathrm{yr}_{\mathrm{I}}\right)$ & \multicolumn{2}{|c|}{5241} \\
\hline
\end{tabular}


TABLE 5

Optimal designs for increasing energy prices

\begin{tabular}{lccccc}
\hline Energy price $(\$ / \mathrm{kWh})$ & 0.03 & 0.04 & 0.05 & 0.06 & 0.08 \\
Mathematical optimum & & & & \\
$\quad$ Total costs $(\$ / \mathrm{yr})$ & 4724 & 4947 & 5130 & 5286 & 5546 \\
Pumping costs ${ }^{2}$ & 15.9 & 16.2 & 16.4 & 16.5 & 16.8 \\
& & & & \\
Final design & & & & & \\
$D(\mathrm{~m})$ & 1.113 & 1.172 & 1.219 & 1.259 & 1.325 \\
$L(\mathrm{~m})$ & 5.188 & 5.047 & 4.943 & 4.859 & 4.730 \\
$B(\mathrm{~m})$ & 1.038 & 1.009 & 0.989 & 1.215 & 1.183 \\
$n$ & 517 & 574 & 623 & 667 & 741 \\
$X$ & 1.633 & 1.635 & 1.636 & 1.637 & 1.638 \\
$U^{b}\left(\mathrm{~J} / \mathrm{C} \sec \mathrm{m}^{2}\right)$ & 32.38 & 30.47 & 29.04 & 26.25 & 24.70 \\
$A^{2}\left(\mathrm{~m}^{2}\right)$ & 182 & 197 & 209 & 220 & 238 \\
$v_{1}(\mathrm{~m} / \mathrm{sec})$ & 13.2 & 11.9 & 10.9 & 10.2 & 9.2 \\
$v_{2}(\mathrm{~m} / \mathrm{scc})$ & 6.7 & 6.5 & 6.4 & 5.0 & 4.9 \\
$\eta \quad$ & 0.0072 & 0.0061 & 0.0055 & 0.0041 & 0.0035 \\
Depreciation $(\$ / \mathrm{yr})$ & 3963 & 4148 & 4301 & 4403 & 4616 \\
Pumping costs $(\$ / \mathrm{yr})$ & 735 & 841 & 940 & 838 & 954 \\
Total costs $(\$ / \mathrm{yr})$ & 4698 & 4989 & 5241 & 5242 & 5570 \\
\hline
\end{tabular}

$a_{\text {In } \% \text { of total costs. }} b_{\text {Referring to inner surface. }}$

expected, increasing the energy price increases both the investment and the pumping costs; rather surprisingly, however, their ratio remains to all practical purposes constant, as follows from the third row of this table. Again the differences and between the total costs of the mathematical optima and of the final designs are satisfactorily small.

Table 6 gives optimal designs for a number of standard tubes. From this table it appears that shell diameter hardly depends on tube diameter, that pitch ratio depends on tube diameter if constraints do not interfere; and that tube length and number of tubes are strongly dependent. The two last effects, however, cancel each other to a considerable degree because heat exchanger surface is rather less dependent on tube diameter.

These results also answer the question why tube diameter has not been introduced as a continuous decision variable and the optimal diameter rounded off to its nearest standard values as has been done with num- ber of baffles. This strategy could only have been followed with some confidence if the optimal pitch ratio and heat exchanging surface had been as nearly constant as the shell diameter.

As can be seen from Table 6, the optimal designs for tube diameters less then 21.3 $\mathrm{mm}$ are too optimistic: in these cases the number of baffles is too low to warrant the use of the approximate $\epsilon-$ NTU relation. The rigorous relation results in higher values of NTU and as a consequence in more expensive designs. At a diameter of $21.3 \mathrm{~mm}$ for instance the mathematical optimum changes to $5824 \$ / y r$. The optimal value of the tube diameter therefore, is $26.9 \mathrm{~mm}$.

According to Fraas and Ozisik [5] it has been found that if the ratio $\eta$ of the pumping power requirement to the heat transmitted through the heat exchanger has a value between 0.005 and 0.01 , the overall cost is usually fairly close to the minimum obtainable. All the minima we found confirm this statement, with the exception of the minima at an energy price of $0.08 \$ / \mathrm{kWh}$. 
TABLE 6

Optimal designs for increasing tube diameters

\begin{tabular}{|c|c|c|c|c|c|}
\hline Energy price $(\$ / \mathrm{kWh})$ & 0.05 & 0.05 & 0.05 & 0.05 & 0.05 \\
\hline$d_{\mathrm{o}}(\mathrm{mm})$ & 13.5 & 17.2 & 21.3 & 26.9 & 33.7 \\
\hline$d_{\mathrm{w}}(\mathrm{mm})$ & 2.35 & 2.35 & 2.65 & 2.65 & 3.25 \\
\hline \multicolumn{6}{|l|}{ Mathematical optimum } \\
\hline Total costs $(\$ / y r)$ & 5507 & 4977 & 4929 & 5130 & 5542 \\
\hline Pumping costs ${ }^{a}$ & 23.0 & 19.8 & 18.1 & 16.4 & 15.4 \\
\hline \multicolumn{6}{|l|}{ Final design } \\
\hline$D(\mathrm{~m})$ & 1.281 & 1.247 & 1.259 & 1.219 & 1.211 \\
\hline$L(\mathrm{~m})$ & 1.762 & 2.621 & 3.467 & 4.943 & 6.562 \\
\hline$B(\mathrm{~m})$ & 0.881 & 1.311 & 1.156 & 0.989 & 1.094 \\
\hline$n$ & 2838 & 1632 & 1068 & 623 & 402 \\
\hline$X$ & 1.659 & 1.650 & 1.650 & 1.636 & 1.594 \\
\hline$U^{b}\left(\mathrm{~J} /{ }^{\circ} \mathrm{Csec} \mathrm{m}^{2}\right)$ & 42.65 & 32.38 & 30.63 & 29.04 & 26.63 \\
\hline$A^{b}\left(\mathrm{~m}^{2}\right)$ & 138 & 168 & 186 & 209 & 225 \\
\hline$v_{1}(\mathrm{~m} / \mathrm{sec})$ & 14.5 & 12.5 & 11.6 & 10.9 & 10.7 \\
\hline$v_{2}(\mathrm{~m} / \mathrm{sec})$ & 6.8 & 4.7 & 5.2 & 6.4 & 6.1 \\
\hline$\eta$ & 0.0080 & 0.0053 & 0.0050 & 0.0055 & 0.0052 \\
\hline Depreciation $(\$ / y r)$ & 4278 & 3981 & 4030 & 4301 & 4690 \\
\hline Pumping costs $(\$ / y r)$ & 1358 & 897 & 854 & 940 & 883 \\
\hline Total costs $(\$ / y r)$ & 5636 & 4878 & 4884 & 5241 & 5574 \\
\hline
\end{tabular}

$a_{\text {In } \% \text { of total costs. }}{ }^{b}$ Referring to inner surface.

\section{LIST OF SYMBOLS}

\section{Latin characters}

$\begin{array}{ll}A & \text { heat exchanging surface }\left(\mathrm{m}^{2}\right) \\ A_{\mathrm{c}} & \text { cross sectional area }\left(\mathrm{m}^{2}\right) \\ A_{\mathrm{X}} & \text { factor defined in text } \\ B & \text { baffle distance }(\mathrm{m}) \\ C & \text { capacity flow }\left(\mathrm{J} /{ }^{\circ} \mathrm{C} \text { sec) }\right. \\ C_{\mathrm{f}}, C_{\mathrm{n}} & \text { factors in Colburn equations } \\ c_{\mathrm{p}} & \text { heat capacity }\left(\mathrm{J} /{ }^{\circ} \mathrm{C} \mathrm{kg}\right) \\ d & \text { diameter or thickness }(\mathrm{m}) \\ D & \text { shell diameter }(\mathrm{m}) \\ \mathrm{Eu} & \text { Euler number } \\ F & \text { objective function }(\$ / \mathrm{yr}) \\ f & \text { friction factor } \\ j \mathrm{~h} & \text { Colburn factor } \\ L & \text { length of flow path }(\mathrm{m}) \\ \mathrm{NTU} & \text { number of overall transfer units } \\ n & \text { number of tubes } \\ \mathrm{ntu} & \text { number of partial transfer units } \\ \mathrm{Pr} & \text { Prandtl number } \\ p & \text { pressure }\left(\mathrm{N} / \mathrm{m}^{2}\right) \\ \mathrm{Re} & \text { Reynolds number } \\ r \mathrm{~h} & \text { hydraulic radius }(\mathrm{m}) \\ \mathrm{St} & \text { Stanton number } \\ s & \text { centre-to-centre distance of tubes }(\mathrm{m}) \\ t & \text { temperature }\left({ }^{\circ} \mathrm{C}\right) \\ u & \text { fouling factor }\left(\mathrm{J} /{ }^{\circ} \mathrm{C} \text { sec } \mathrm{m}^{2}\right)\end{array}$

$U \quad$ overall heat transfer coefficient $\left(\mathrm{J} /{ }^{\circ} \mathrm{C} \mathrm{sec} \mathrm{m}^{2}\right)$

$v \quad$ linear velocity $(\mathrm{m} / \mathrm{sec})$

$W \quad$ frictional resistance energy $(\mathrm{J} / \mathrm{kg})$

$X \quad$ pitch ratio

\section{Greek characters}

$\begin{array}{ll}\alpha & \text { partial heat transfer coefficient }\left(\mathrm{J} /{ }^{\circ} \mathrm{Csec} \mathrm{m}^{2}\right) \\ \beta & \text { ratio defined in text } \\ \gamma & \text { ratio of capacity flows } \\ \epsilon & \text { heat transfer effectiveness } \\ \eta & \text { energy ratio defined in text } \\ \lambda & \text { thermal conductivity }\left(\mathrm{J} /{ }^{\circ} \mathrm{C} \mathrm{sec} \mathrm{m}\right) \\ \nu & \text { kinematic viscosity }\left(\mathrm{m}^{2} / \mathrm{sec}\right) \\ \rho & \text { density }\left(\mathrm{kg} / \mathrm{m}^{3}\right) \\ \phi & \text { volume flow }\left(\mathrm{m}^{3} / \mathrm{sec}\right)\end{array}$

Subscripts, not defined above

$\begin{array}{ll}\mathrm{c} & \text { cold } \\ \mathrm{h} & \text { hot } \\ \text { in } & \text { in } \\ \mathrm{k} & \text { index } \\ \text { out } & \text { out } \\ \text { min } & \text { minimum } \\ \max & \text { maximum } \\ \mathrm{w} & \text { wall } \\ 1 & \text { inside tubes } \\ 2 & \text { outside tubes }\end{array}$




\section{REFERENCES}

1 Kays, W.M. and London, A.L., 1964. Compact Heat Exchangers, McGraw-Hill, New York.

2 Dodge, B.F., 1944. Chemical Engineering Thermodynamics, McGraw-Hill, New York.

3 V.D.I., 1963. Wärmeatlas, V.D.I.-Verlag, Dusseldorf.

4 Lee, W., Christensen, J.H. and Rudd, D.F., 1966. A.I.Ch.E. Journal, 12(6): 1104.

5 Fraas, A.P. and Ozisik, M.N., 1965. Heat Exchanger Design, John Wiley \& Sons, New York.

6 Chilton, C.H. (Ed.), 1960. Cost Engineering in the Process Industries, McGraw-Hill, New York.

7 Guthrey, K.M., 1969. Chem. Eng., 24(3): 114.

8 Palen, J.W., Cham, T.P. and Taborek, J., 1974. A.I.Ch.E. Symp. Series, 70 (138): 205.

9 Nelder, J.A. and Mead, R., 1965. Computer J., 7 : 308.

10 Fontein, H.J. and Groot Wassink, J., 1974. Verfahrenstechnik, 8: 200.

11 Lootsma, F.A., 1970. Boundary Properties of Penalty Functions for Constrained Minimizations, Ph.D. Thesis, Technical University of Eindhoven, The Netherlands.

\section{BIOGRAPHICAL NOTE}

H.J. Fontein is a senior research worker in the Chemical Engineering Department at the Twente University of Technology, where he specializes in the application of optimization methods to the design of chemical plants. A chemical engineering graduate of the Delft Technological University, he previously worked in industry for many years.

J. Groot Wassink is a professor of process engineering in the same Department at Twente. He holds two master's degrees, in chemical engineering from Delft and in philosophy from the catholic university of Nijmegen. He has many years industrial experience in chemical process design, production and management. 